\title{
Collapse behaviour of unsaturated compacted soil with different initial densities
}

\author{
De'an Sun, Daichao Sheng, and Yongfu Xu
}

\begin{abstract}
Very few experimental data on the mechanical behaviour of unsaturated soils exists, particularly on the collapse behaviour under general stress states, because of the technical difficulties and time-consuming nature of measuring suction and deformation. This paper presents the results of a series of controlled-suction triaxial tests on the collapse behaviour of an unsaturated compacted clay with different initial dry densities and suctions. The collapse behaviour here includes deformation characteristics, such as volume changes, and hydraulic characteristics, such as saturation changes. It is found that the wetting-caused collapse mainly depends on the mean net stress and the initial density, and that the volume decrease reaches a maximum when the specimen is under the initial yielding mean net stress. It is also found that the soil-water characteristic curve in terms of suction and degree of saturation shifts upwards with increasing specimen density. The soil-water characteristic curve of a compacted soil mainly depends upon the current density, not directly upon the stress state. In addition, experimental data show that the collapse occurs mainly in an intermediate range of suction levels, which are neither very high nor very low, and that the wetting-caused volume decrease is accompanied by an increase in the degree of saturation.
\end{abstract}

Key words: unsaturated soil, density, triaxial test, suction, collapse, degree of saturation.

Résumé : À cause des difficultés techniques et de la longue durée de temps requises pour la mesure de la succion et de la déformation, il existe très peu de données expérimentales sur le comportement mécanique des sols non saturés, et particulièrement sur le comportement de l'effondrement sous des états généraux de contraintes. Cet article présente les résultats d'une série d'essais triaxiaux à succion contrôlée pour étudier le comportement en effondrement d'une argile compactée non saturée avec différentes densités sèches et succions initiales. Le comportement en effondrement inclut ici les caractéristiques de déformation telles que les changements de volume et les caractéristiques hydrauliques comme les changements de saturation. On trouve que l'effondrement causé par le mouillage dépend principalement de la contrainte moyenne nette et de la densité initiale, et la diminution de volume atteint un maximum lorsque le spécimen est sous la contrainte initiale moyenne nette de limite élastique. On trouve également que la courbe caractéristique sol-eau en fonction de la succion et du degré de saturation bouge vers le haut avec l'augmentation de la densité du spécimen. La courbe caractéristique sol-eau d'une sol compacté dépend principalement de la densité en cours, et non directement de l'état de contrainte. De plus, les données expérimentales montrent que l'effondrement se produit principalement dans le domaine intermédiaire des niveaux de succion qui sont ni très hauts, ni très bas, et que la diminution de volume produite par le mouillage est accompagnée par une augmentation du degré de saturation.

Mots-clés : sol non saturé, densité, essai triaxial, succion, effondrement, degré de saturation.

[Traduit par la Rédaction]

\section{Introduction}

Experimental data on unsaturated soil behaviour in controlled-suction triaxial tests have been used to establish and validate elastoplastic constitutive models (Alonso et al. 1990; Wheeler and Sivakumar 1995, 2000; Maatouk et al. 1995; Cui and Delage 1996; Rampino et al. 1998; Kato and Kawai 2000; Sivakumar and Wheeler 2000; Sun et al. 2000, 2004; Wang et al. 2002). For example, Wheeler and Sivakumar (1995) conducted a series of controlled-suction triaxial tests on compacted kaolin to validate the model pro- posed by Alonso et al. (1990), and their data indeed provided some support for the model. Maatouk et al. (1995) studied the influence of initial density on the isotropic compression behaviour using limited data from controlledsuction tests and concluded that the slope of the compression line (i.e., compression index) of an unsaturated compacted silt decreases with increasing initial density. Kato and Kawai (2000) were among the first to systematically study the collapse behaviour of compacted soils in controlled-suction isotropic compression and triaxial tests, but their studies were limited to one single density of the

Received 18 July 2005. Accepted 30 January 2007. Published on the NRC Research Press Web site at cgj.nrc.ca on 18 July 2007.

D.A. Sun ${ }^{1}$. Department of Civil Engineering, Shanghai University, 149 Yanchang Road, Shanghai 200072, China.

D.C. Sheng. School of Engineering, The University of Newcastle, Callaghan, NSW 2308, Australia.

Y.F. Xu. Department of Civil Engineering, Shanghai Jiaotong University, Shanghai 200030, China.

${ }^{1}$ Corresponding author (e-mail: sundean06@163.com) 
Fig. 1. The grading curve of Pearl clay.

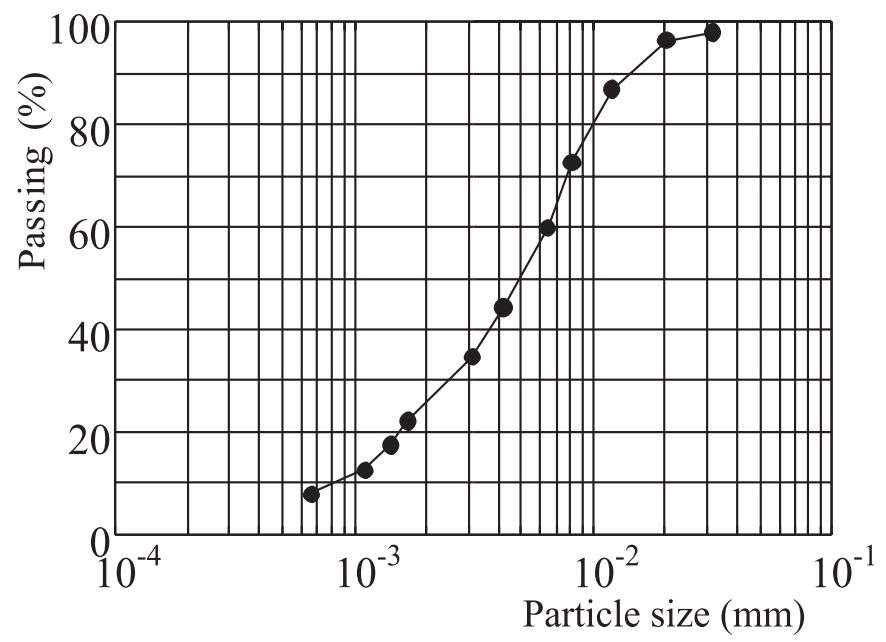

soil. More recently, Sun et al. (2004) conducted a series of collapse tests, using a controlled-suction triaxial cell, to study the factors influencing the deformation characteristics of compacted soils during wetting-induced collapse.

Recent research on unsaturated soil behaviour has led to consistent treatment of both the mechanical behaviour and the hydraulic behaviour of unsaturated soils under the same elastoplastic framework (Vaunat et al. 2000; Wheeler et al. 2003; Sheng et al. 2004; Sun and Sheng 2005). In other words, a complete constitutive model for unsaturated soil behaviour consists of a mechanical part dealing with the stress-strain relation as well as a hydraulic part dealing with the suction-saturation relation. The two relations are formulated in a consistent way based on plasticity and thermodynamic theories. As such, we need to understand the collapse behaviour of unsaturated soils both in terms of deformation characteristics (such as volume change) and in terms of hydraulic characteristics (such as saturation change). In this sense, this paper is an extension of the previous work by Sun et al. (2004) on the collapse behaviour of unsaturated compacted clays, with renewed focuses and experimental data on deformation and hydraulic characteristics.

The main objective of this paper is to investigate the influences of the initial density and the stress conditions on the wetting-induced collapse behaviour of an unsaturated compacted clay under suction control. Here the collapse behaviour is considered to cover the deformation characteristics as well as the hydraulic behaviour. To investigate these influences, a series of controlled-suction triaxial tests were performed on an unsaturated compacted clay with different initial densities. The experimental program consists of isotropic compression tests under either constant or varying suctions and triaxial tests under either constant or varying suctions.

\section{Experimental program}

A laboratory experimental program was designed whose main objective was to investigate the influences of the initial density and stress conditions on the deformation and hydraulic characteristics of unsaturated compacted soils during wetting-induced collapse processes.

\section{Testing material and specimen preparation}

The soil used in this study is called Pearl clay. It has a liquid limit of $49 \%$, a plasticity index of 22, and a specific gravity of 2.71. Figure 1 shows the grading curve of Pearl clay. Figure 2 shows the results of an X-ray diffraction test on the soil. It can be seen that the clay is nonexpansive, containing quartz, pyrophyllite, and kaolinite in the order of dominance. Soil particles were air-dried and then mixed with the required amount of water to reach a specific water content. The soil was then wrapped in polyethylene bags and stored in a room with constant temperature and humidity for several days to reach equilibrium.

Triaxial specimens, $35 \mathrm{~mm}$ in diameter and $80 \mathrm{~mm}$ in height, were prepared by compaction in a mould at water content of about $26 \%$. Most specimens were compacted in five layers, and each layer was statically compacted using a $12 \mathrm{~mm}$ diameter plunger to a vertical stress of $300 \mathrm{kPa}$, $400 \mathrm{kPa}$, or $600 \mathrm{kPa}$. The procedure, with the initial water content of about $26 \%$ and the number of blows per layer varying from 5 to 25 , results in a void ratio ranging from 1.0 to 1.5 , a degree of saturation ranging from $40 \%$ to $65 \%$, and an initial suction from $90 \mathrm{kPa}$ to $130 \mathrm{kPa}$. Figure 3 shows the compaction curves for Pearl clay with 15 blows per layer and vertical compaction stresses of $300 \mathrm{kPa}, 400 \mathrm{kPa}$, and $600 \mathrm{kPa}$. Contours of equal degrees of saturation are also shown in the figure. All the tested specimens are on the dry side of the optimum.

\section{Triaxial apparatus for unsaturated soils}

Figure 4 shows the triaxial apparatus used for testing unsaturated soils. It can directly measure the change in specimen diameter and can control the stress state and matric suction. The main parts of the apparatus are the same as those used previously by Kato and Kawai (2000) and Sun et al. (2000), except for the lateral displacement measurement. The lateral displacements of the specimen are measured using three rings made of stainless steel or bronze mounted at $H / 4, H / 2$, and $H$ from the top of the specimen as shown in Figs. 4 and 5, where $H$ is the specimen height and $D_{1}, D_{2}$, and $D_{3}$ are the measured diameters according to the three lateral displacement meters. The lateral shape of the specimen is approximated by a third-order polynomial, as shown in Fig. 5. From the geometry, the specimen volume can be calculated by

$$
V=2 \int_{0}^{H / 2} \pi x^{2} \mathrm{~d} y=2 \pi \int_{0}^{H / 2}\left(a y^{3}+b y^{2}+d\right)^{2} \mathrm{~d} y=\pi\left(\frac{a^{2} H^{7}}{448}+\frac{a b H^{6}}{96}+\frac{b^{2} H^{5}}{80}+\frac{a d H^{4}}{16}+\frac{b d H^{3}}{6}+d^{2} H\right)
$$


Fig. 2. X-ray diffraction plot of Pearl clay. CPS, counts per second.

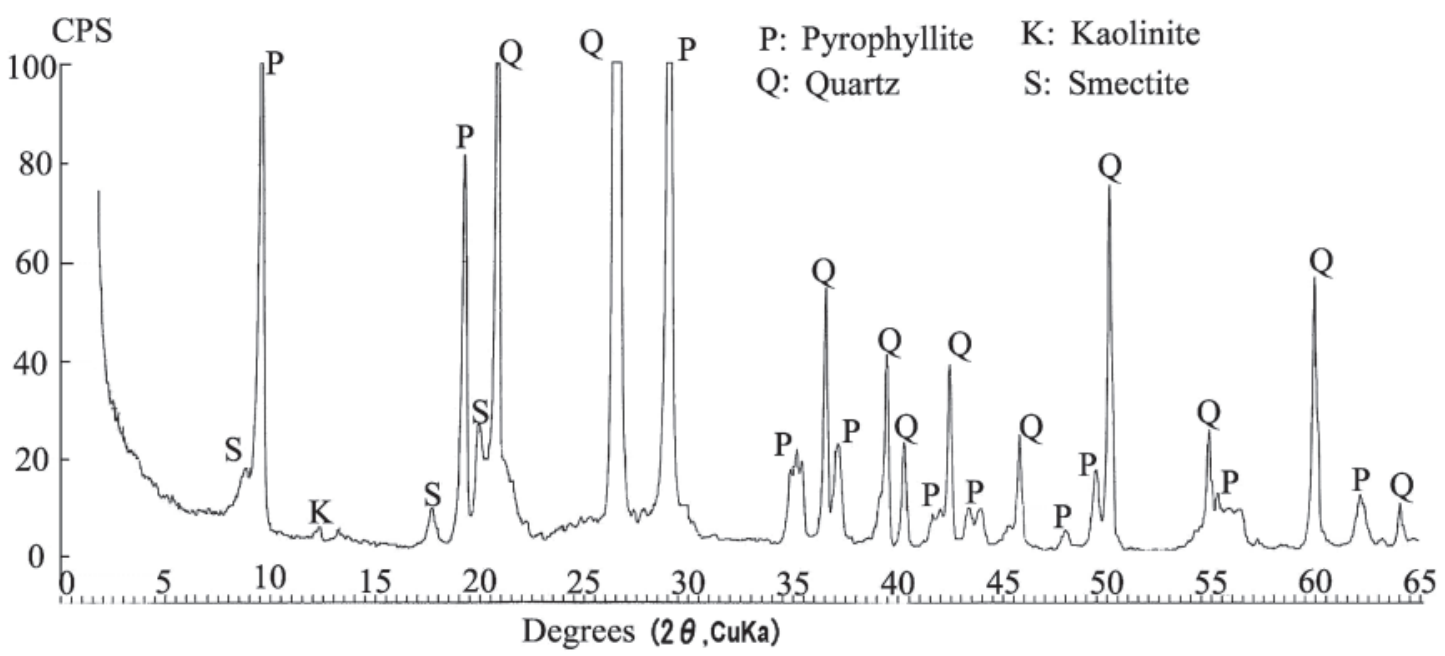

Fig. 3. Compaction curve for Pearl clay. Max. comp. stress, maximum compression stress.

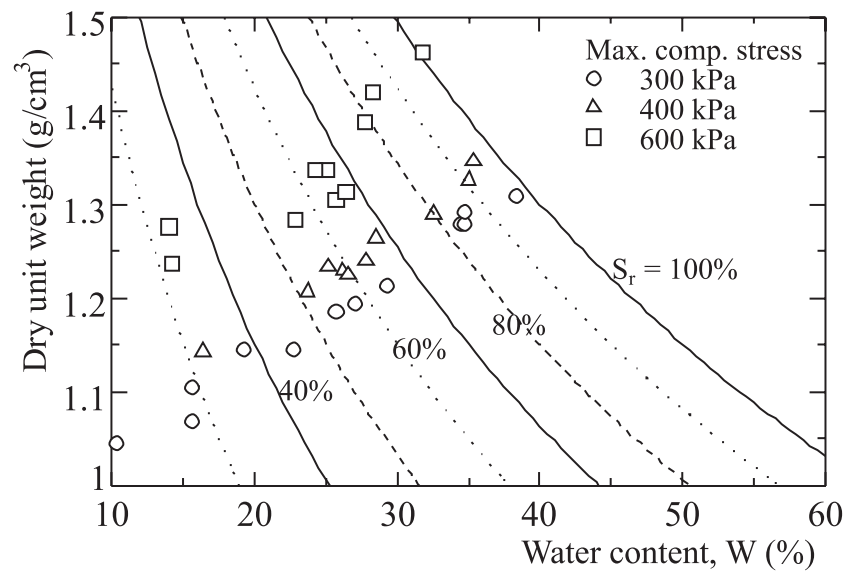

where

$$
\begin{aligned}
& \text { [2] } a=\frac{8}{H^{3}}\left(D_{3}-4 D_{1}+3 D_{2}\right) \\
& \text { [3] } \quad b=\frac{2}{H^{2}}\left(8 D_{1}-D_{3}-7 D_{2}\right)
\end{aligned}
$$$$
\text { [4] } \quad d=\frac{D_{2}}{2}
$$

With known values of $D_{1}, D_{2}, D_{3}$, and $H$, the specimen volume can be calculated using the above equations. To check the accuracy of the method used for determining the lateral displacements of the specimen, an isotropic compression test on saturated and normally consolidated Pearl clay was performed. In Fig. 6, the $e-\log p$ curve obtained from lateral displacement meters is compared to those obtained from direct measurement of the volume using a burette. It can be seen that the two curves are very similar. Hence, the accuracy of determining the lateral strain by this method is confirmed.
Fig. 4. Schematic layout of the triaxial apparatus for testing unsaturated soils. DPT, differential pressure transducer.

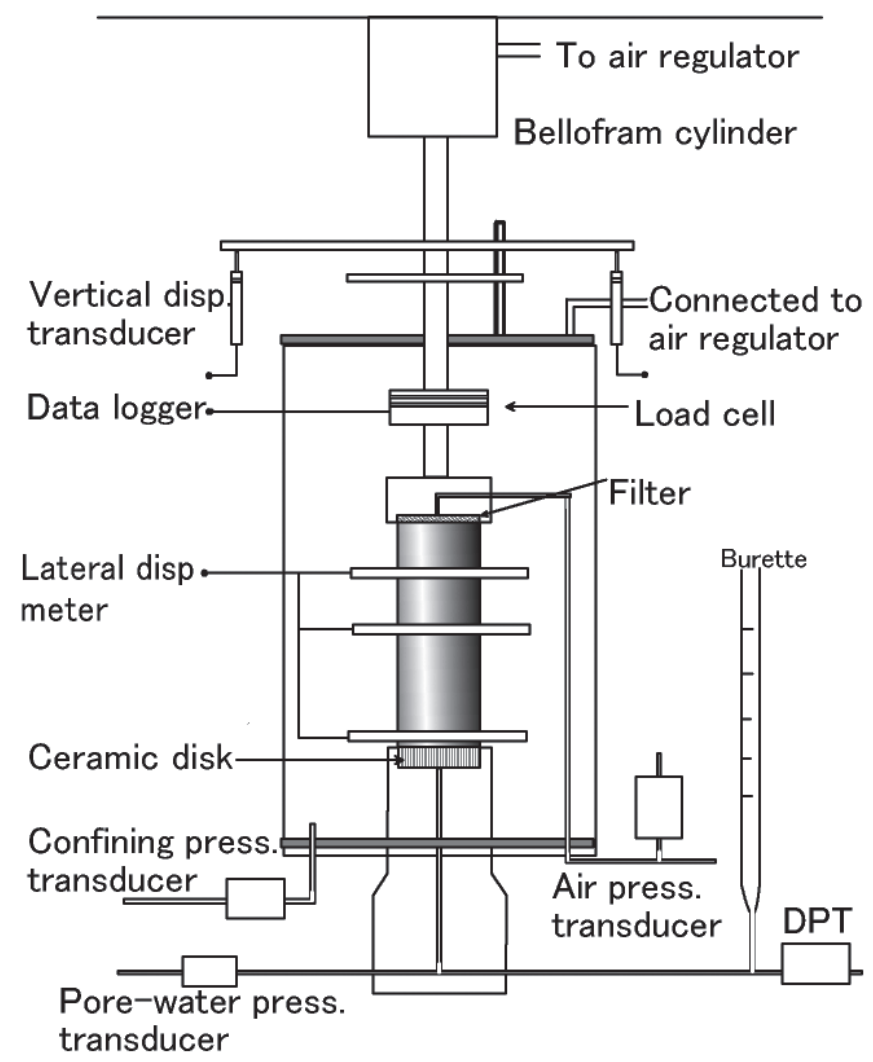

As shown in Fig. 4, the pore-water pressure is measured by a pressure transducer that is installed beneath a ceramic disk with an air-entry value of $300 \mathrm{kPa}$, while the air pressure is applied at the top through a polyflon filter that can prevent the water within the specimen from seeping out of the upper porous stone. Hence, the water change in the burette is the same as that in the specimen and therefore the water content can be calculated. Suction control is realised by adopting the axistranslation technique (Hilf 1956), that is, an air pressure equal to the imposed suction is applied with the pore-water pressure 
Fig. 5. Determination of the specimen volume by height and three diameters at different levels.

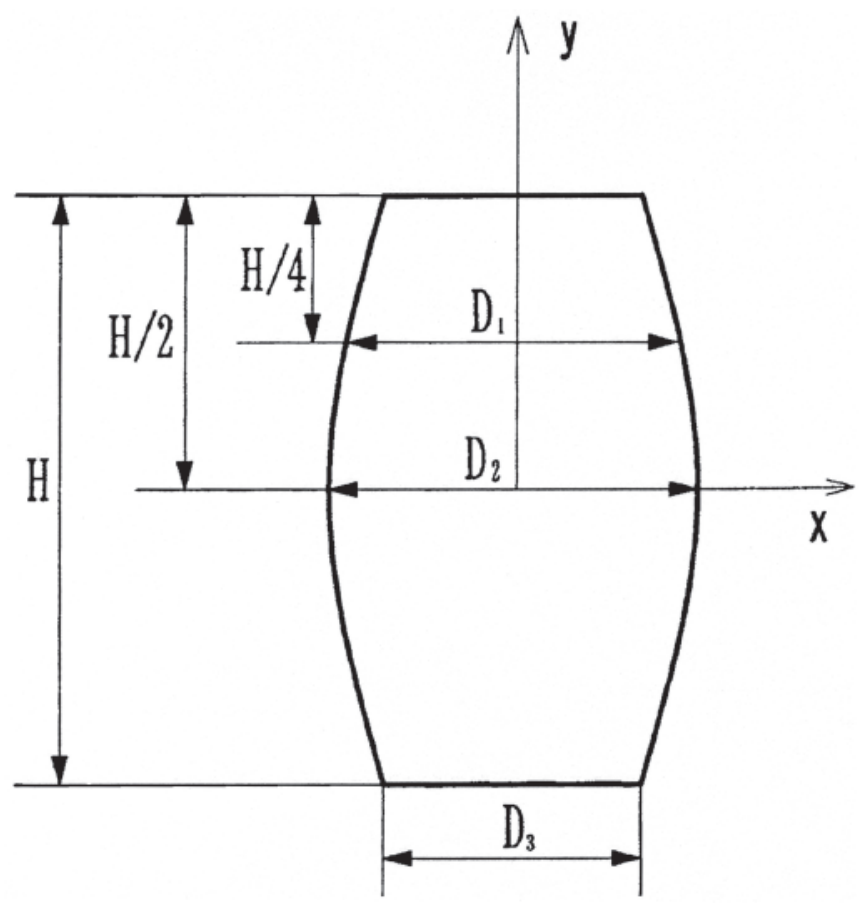

kept at the atmospheric pressure. The ceramic disk was carefully saturated before use so that water can freely flow through the disk during the collapse tests. Based on recent experimental data (Padilla et al. 2006), the ceramic disk with an air-entry value of $300 \mathrm{kPa}$ does not generate a measurable amount of diffused air and can thus be used without a diffused air measurement, even at the air-entry value pressure. In this study, the imposed suction varies from 0 to $147 \mathrm{kPa}$, which is less than $50 \%$ of the air-entry value of the used ceramic disk. Therefore, the diffused air in the pore-water system was not measured. During the tests, temperature variations were controlled within $20 \pm 1{ }^{\circ} \mathrm{C}$.

\section{Testing procedures}

Soil specimens were first isotropically consolidated to a mean total stress $p_{\mathrm{t}}$ of $20 \mathrm{kPa}$ and a pore-air pressure $u_{\mathrm{a}}$ of $0 \mathrm{kPa}$ under undrained conditions. A specific air pressure greater than the absolute initial pore-water pressure was applied to the specimen with the mean net stress $p$ kept at $20 \mathrm{kPa}$, where the mean net stress $p$ was equal to $p_{\mathrm{t}}-u_{\mathrm{a}}$. The drainage valve connected to the ceramic disk was then opened to achieve a pore-water pressure of $u_{\mathrm{w}}=0$. The specimen was loaded to a previously specified net stress state under a constant suction of $147 \mathrm{kPa}$. The suction was then decreased from $147 \mathrm{kPa}$ to $0 \mathrm{kPa}$ under a constant net stress state for performing a collapse test. Figure 7 shows the imposed stress paths for determining the collapse behaviour of unsaturated compacted soil under $(a)$ isotropic stress conditions and $(b)$ anisotropic stress conditions.

The collapse tests were performed by decreasing the suction from $147 \mathrm{kPa}$ to $0 \mathrm{kPa}$ step by step under drained conditions. This suction decrease was achieved either under isotropic stress states (Fig. 7a) or under triaxial stress states. In the latter case, the specimen was sheared to a specific
Fig. 6. Results of isotropic compression tests on saturated Pearl clay.

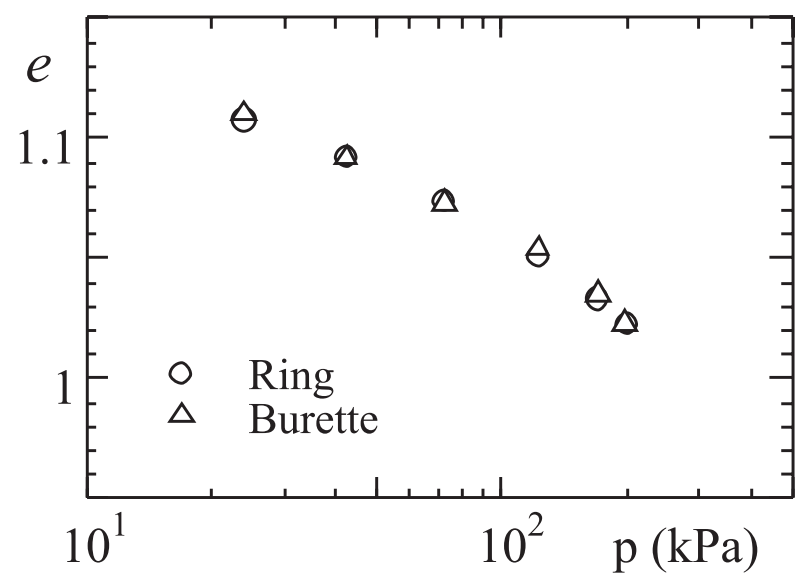

stress ratio under constant mean net stress $(p=196 \mathrm{kPa})$ before the suction decrease (Fig. 7b). During the tests, the pore-water pressure, $u_{\mathrm{w}}$, and the pore-air pressure, $u_{\mathrm{a}}$, were measured at the bottom and top of the specimen, respectively. Sufficient equilibrating time was allowed after every change in the pore-water pressure and the pore-air pressure, so that the suction became almost uniform in the whole specimen. In the collapse test, the de-aired water stored in the burette was introduced from the bottom of the specimen through the ceramic disk. In the last step of the collapse tests, in which the pore-air pressure was kept to zero, the water level in the burette was kept at about 100-300 mm higher than the centre of the specimen to increase the degree of saturation of the specimen, as indicated by Pereira and Fredlund (2000). After most of the collapse tests, a triaxial compression test or a triaxial extension test was performed on the saturated specimen until failure.

Figures 8, 9, and 10 show the results of a test along the stress path ABCDEGG' in Fig. $7 a$ for the entire test, the equalization process, and the collapse process, respectively. In these figures, the time, the volumetric strain $\left(\varepsilon_{\mathrm{v}}\right)$, and the water change $\left(\Delta V_{\mathrm{w}}\right)$ were all counted from the beginning of the test. A negative value of $\Delta V_{\mathrm{w}}$ means that water was absorbed to the specimen from the burette. It can be seen from Figs. 8 and 9 that some water outflow occurs during the isotropic consolidation under a constant suction of $147 \mathrm{kPa}$ (see the segment CDEFG). The initial suction of the tested specimen is about $110 \mathrm{kPa}$ (see the segment BC in Fig. 9a). From Fig. 10, we can see that a volume decrease and a water inflow can take place simultaneously with decreasing suction, but under a constant net stress.

\section{Experimental results and discussions}

\section{Collapse behaviour in isotropic stress}

Figure 11 shows the results of isotropic compression tests and collapse tests on the compacted Pearl clay with $(a) e_{0 \mathrm{a}}=$ $1.36,(b) e_{0 \mathrm{a}}=1.28,(c) e_{0 \mathrm{a}}=1.17$, and $(d) e_{0 \mathrm{a}}=1.05$, respectively. Here $e_{0 \mathrm{a}}$ is the average initial void ratio of the tested specimen shown in each figure. The imposed stress paths and wetting paths are similar to those shown in Fig $7 a$. All the curves in Fig. 11 show a decrease in the void ratio at $p \approx 20 \mathrm{kPa}$. 
Fig. 7. Stress paths for isotropic compression tests and triaxial tests including collapse tests: $(a)$ isotropic stress and $(b)$ triaxial stress.

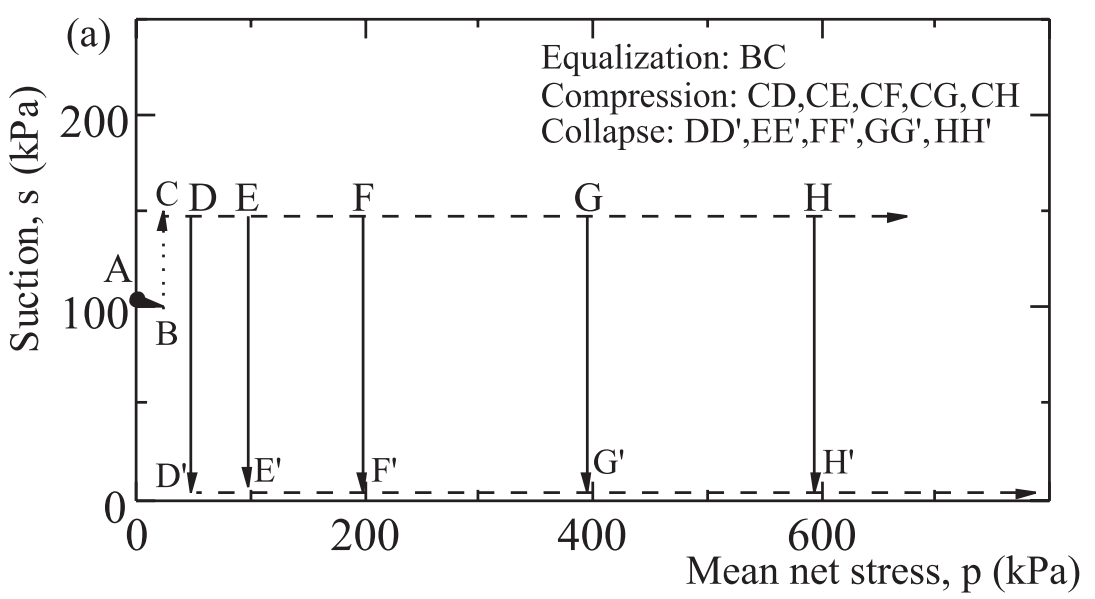

(b)

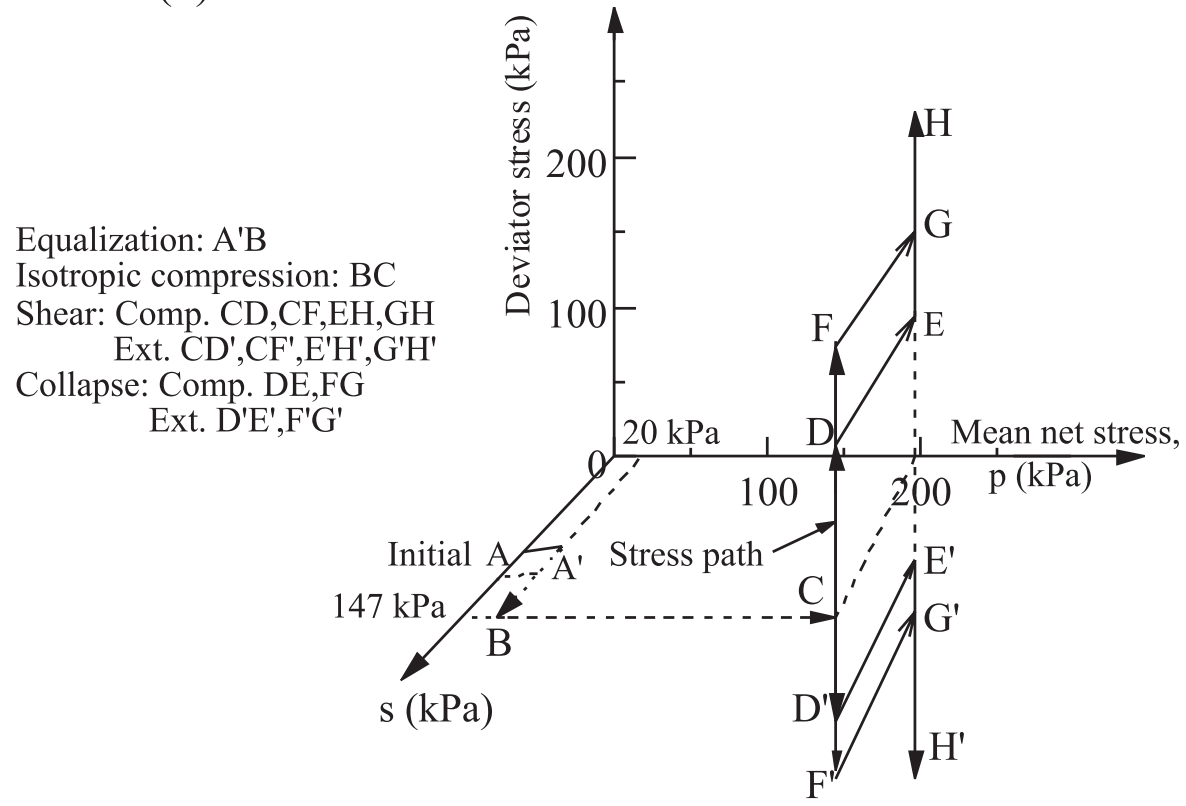

This decrease is due to the suction increase from the initial suction (about $90-130 \mathrm{kPa}$ ) to $147 \mathrm{kPa}$. The compression curves for saturated soils (i.e., zero suction) locate lower than the curves for the suction of $147 \mathrm{kPa}$, and the slopes of the curves for unsaturated soils under larger mean net stresses are larger than those for the corresponding saturated soil. Therefore, it can be inferred from Fig. 11 that the compression curve for a saturated soil and the corresponding curve for the unsaturated soil converge to a point where no collapse or swelling occurs with any increase or decrease in suction. It is seen from Fig. 11 that the compression curves for saturated soils (suction is equal to zero) obtained from wetting at different mean net stresses are more or less the same, if the initial densities are close. However, these curves are slightly different with different initial densities, and the curve with a smaller initial void ratio tends to be somewhat lower in the $e-\ln p$ space (e.g., Fig. $11 a$ compared with Fig. 11c or Fig. 11d).

Figure 12 shows the collapse strains at different isotropic net stresses at which the suction was reduced from $147 \mathrm{kPa}$ to $0 \mathrm{kPa}$. The collapse volumetric strain is defined as
[5] $\quad \varepsilon_{\mathrm{v}}^{\mathrm{co}}=\frac{-\Delta e_{\mathrm{co}}}{1+e_{\mathrm{b}}}$

where $e_{\mathrm{b}}$ is the void ratio at the beginning of the suction reduction, and $\Delta e_{\mathrm{co}}$ is the difference in the void ratios before and after the suction reduction. From Fig. 12 it can be seen that a larger initial density results in a smaller collapse volumetric strain under the same mean net stress.

From Figs. 11 and 12, we can see that the magnitude of volume collapse, due to a decrease in the suction, depends on the mean net stress and the initial void ratio, and that the maximum collapse for identically compacted specimens occurs when wetting takes place at a mean net stress close to the initial yield stress. The initial yielding stress for the soil under suction of $147 \mathrm{kPa}$ can be inferred from Fig. 11 and is approximately between 100 and $200 \mathrm{kPa}$. If wetting takes place at a mean net stress greater than the initial yielding stress, a smaller collapse strain occurs. This phenomenon can be explained by the fact that the soil structure begins to degrade once the mean net stress is larger than the initial 
Fig. 8. Full process of equalization, isotropic consolidation, and collapse along stress path ABCDEFGG' in Fig. $7 a$.

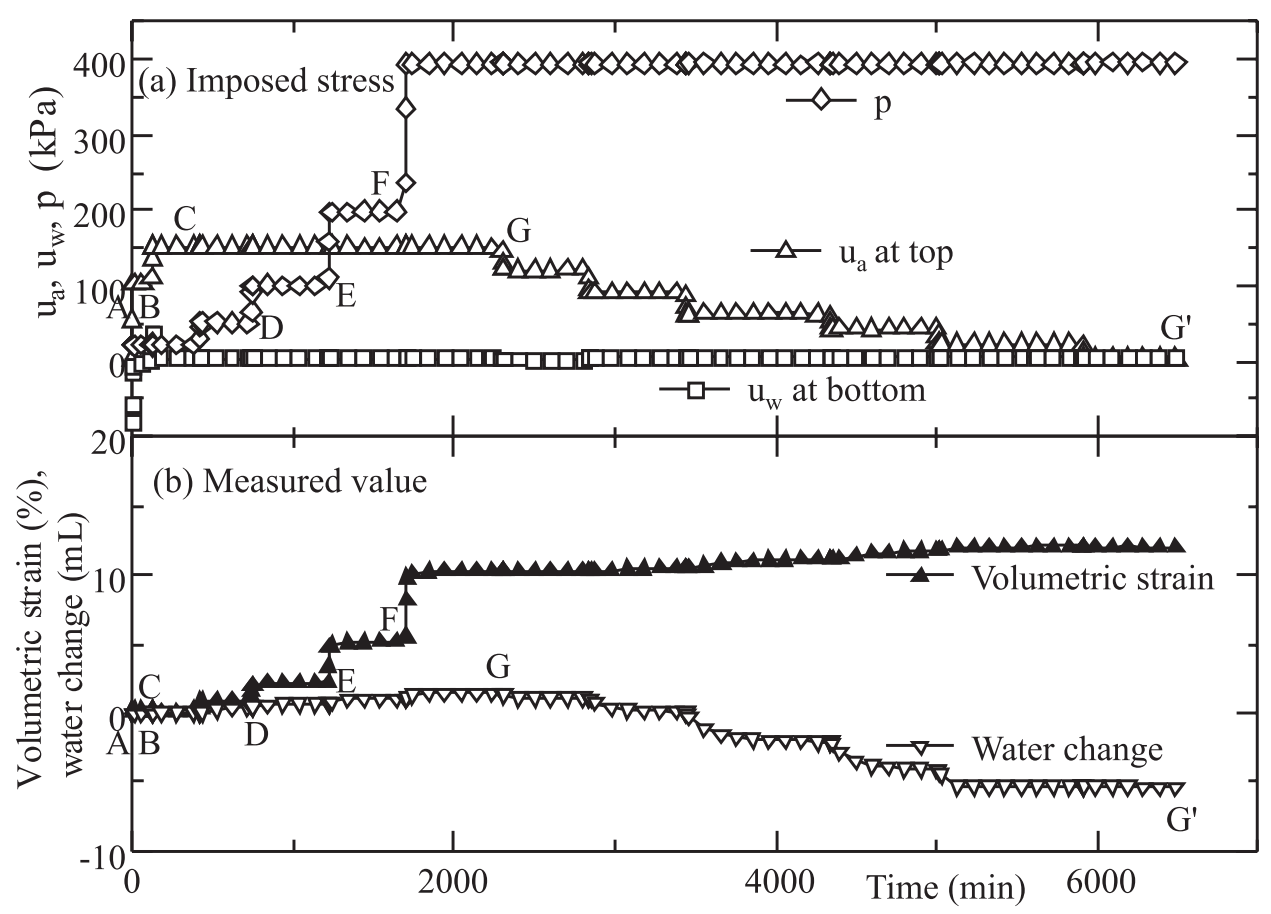

Fig. 9. Measurement of initial suction and equalization along stress path BC in Fig. $7 a$.

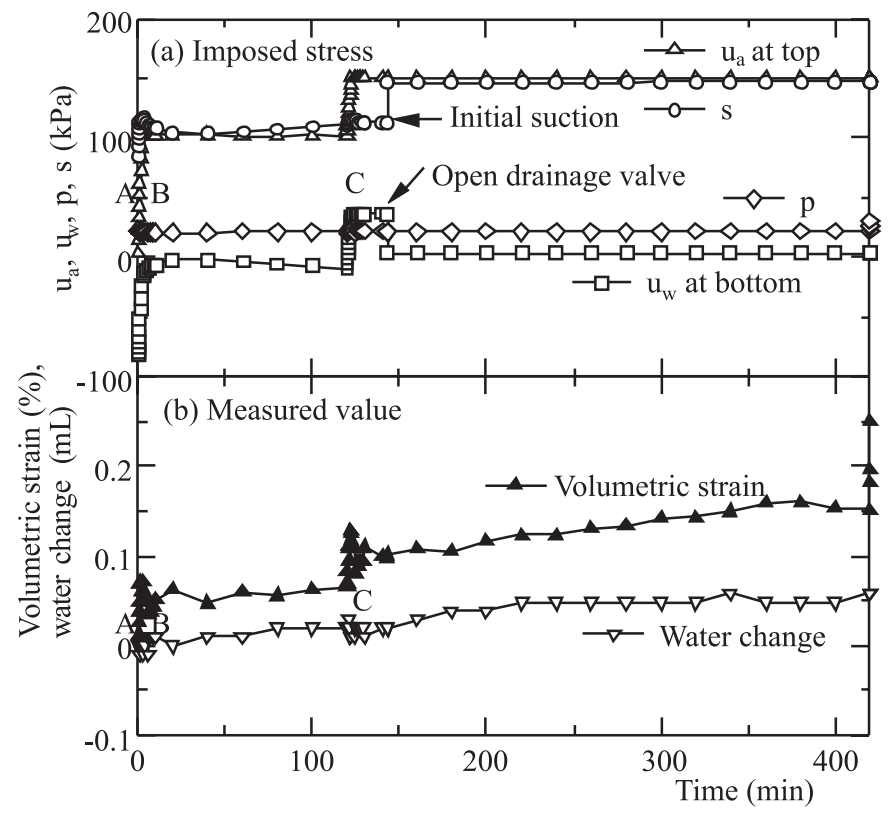

yielding stress. Once destructuration of the soil takes place, the specimen becomes denser, and hence the collapse due to the suction reduction becomes smaller.

Figure 13 shows the relationships between the collapse volumetric strain and the suction, between the water content and the suction, and between the degree of saturation and the suction, obtained from the results of the collapse tests on the compacted Pearl clay that was wetted (the suction was reduced from $147 \mathrm{kPa}$ to $0 \mathrm{kPa}$ ) at different mean net stresses of $20 \mathrm{kPa}, 49 \mathrm{kPa}, 98 \mathrm{kPa}, 196 \mathrm{kPa}, 392 \mathrm{kPa}$, and
Fig. 10. Collapse process along stress path $\mathrm{GG}^{\prime}$ (wetting path) in Fig. $7 a$.

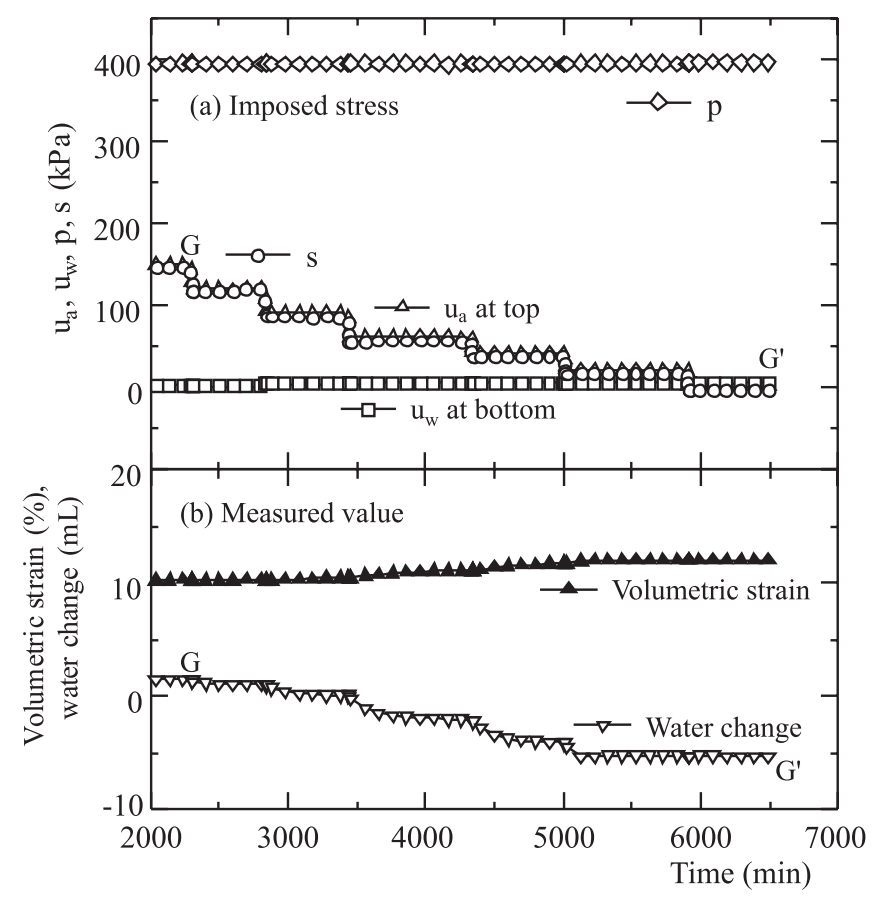

$588 \mathrm{kPa}$. The values of $e_{0}$ and $e_{\mathrm{b}}$ in Fig. 13 are the void ratios before testing and before the suction reduction, respectively. The values of $p$ are the mean net stresses at which the suction is reduced. The relationships between the water content and the suction and between the degree of saturation and the suction are two alternative forms of the soilwater characteristic curve during the wetting process. The suction was reduced from $147 \mathrm{kPa}$ to $0 \mathrm{kPa}$ in two different 
Fig. 11. Volume change of compacted clay with different initial densities during isotropic stress paths and wetting paths.
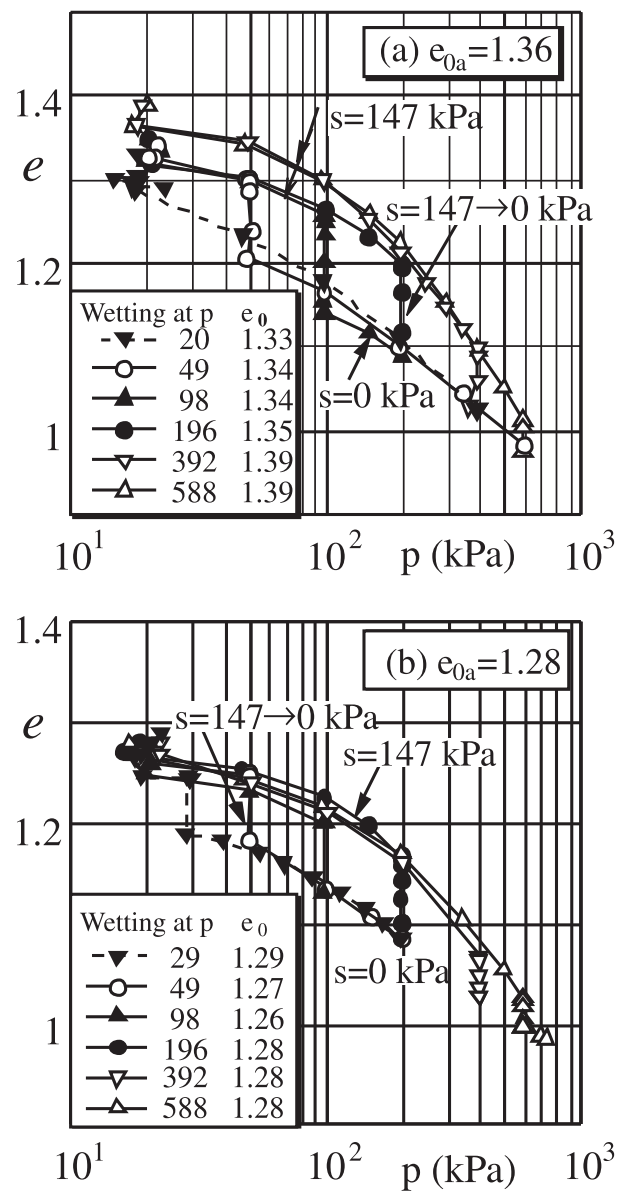

Fig. 12. Collapse at different isotropic stresses for compacted specimens with different initial densities.

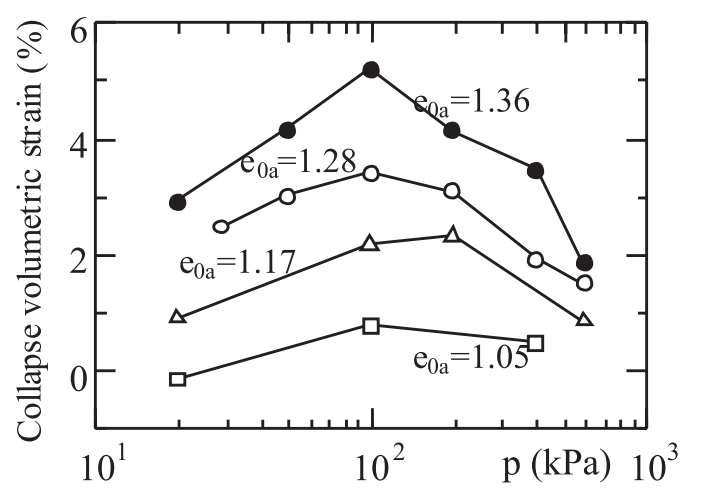

sequences: one in steps of $147 \mathrm{kPa}, 98 \mathrm{kPa}, 49 \mathrm{kPa}$, and $0 \mathrm{kPa}$, and the other in steps of $147 \mathrm{kPa}, 117 \mathrm{kPa}, 88 \mathrm{kPa}$, $59 \mathrm{kPa}, 39 \mathrm{kPa}, 20 \mathrm{kPa}$, and $0 \mathrm{kPa}$. Therefore, there are either four measured points or seven measured points for each collapse test, depending on the number of steps used in the suction reduction. The collapse tests with seven suctionreduction steps are good for identifying the collapse behaviour, but are naturally more time-consuming than the ones with four suction-reduction steps. The last measured point in each wetting test has a very small negative suction. This is because the water level in the burette was higher than the cen-
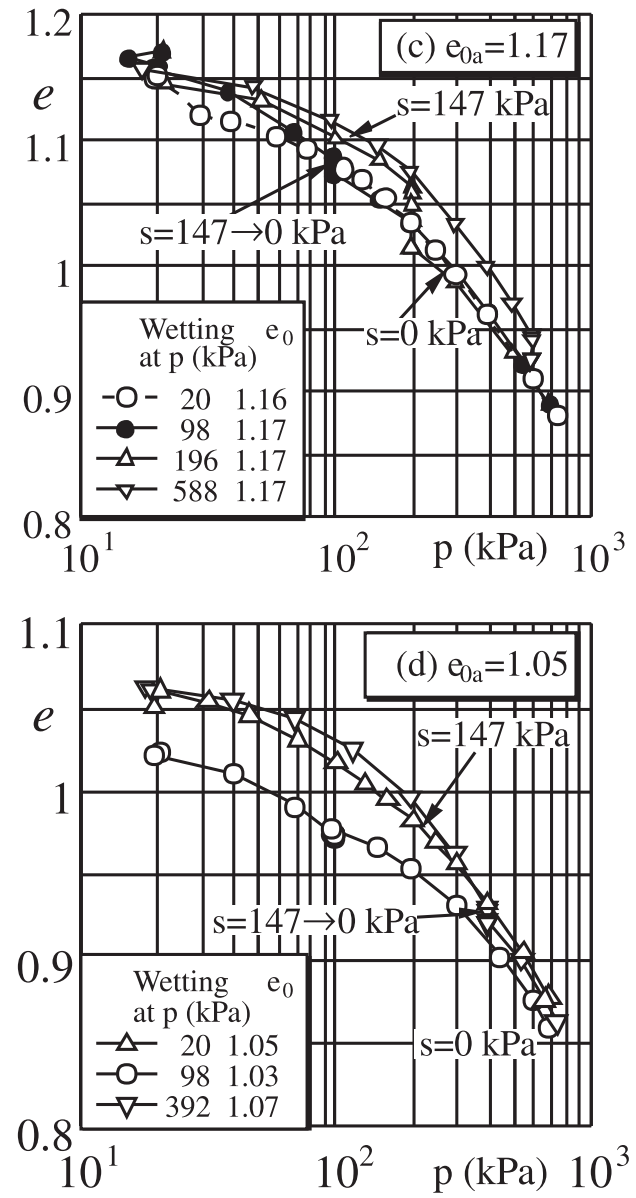

ter of the soil specimen to increase the degree of saturation under $u_{\mathrm{a}}=0$. When the suction was about zero or at a small negative value, the degree of saturation in most wetting tests was between $85 \%$ and $95 \%$. This means that the specimen could not be fully saturated even at zero suction or a small negative suction. Incomplete saturation at zero suction may be attributed to the trapped air in the pores inside the soil specimen and (or) in the testing system.

As can be seen from Fig. 13, the collapse volumetric strain is initially very small at higher suction levels and then becomes larger when the suction is reduced to lower levels. When the suction is reduced to about $100 \mathrm{kPa}$, the collapse volumetric strain is very small or even slightly negative (swelling). This is particularly true when the net stress is relatively small (see Figs. $13 a-13 c$ ). The collapse strain corresponding to the suction reduction between $100 \mathrm{kPa}$ and $20 \mathrm{kPa}$ is relatively large, irrespective of the mean net stress. The collapse volumetric strain around zero suction (from a small positive to a small negative suction) is reduced again (see Figs. 13c-13f). This phenomenon cannot be seen in the test results with only four measured points because there are not enough points present within the suction interval. The reason for this phenomenon can be related to the corresponding relationship between the degree of saturation and the suction in the same figure. The volume collapse seems to correspond to the increase in the degree of saturation more simultaneously than to the de- 
Fig. 13. Collapse process during the suction reduction from $147 \mathrm{kPa}$ to $0 \mathrm{kPa}$ at different net isotropic stresses.
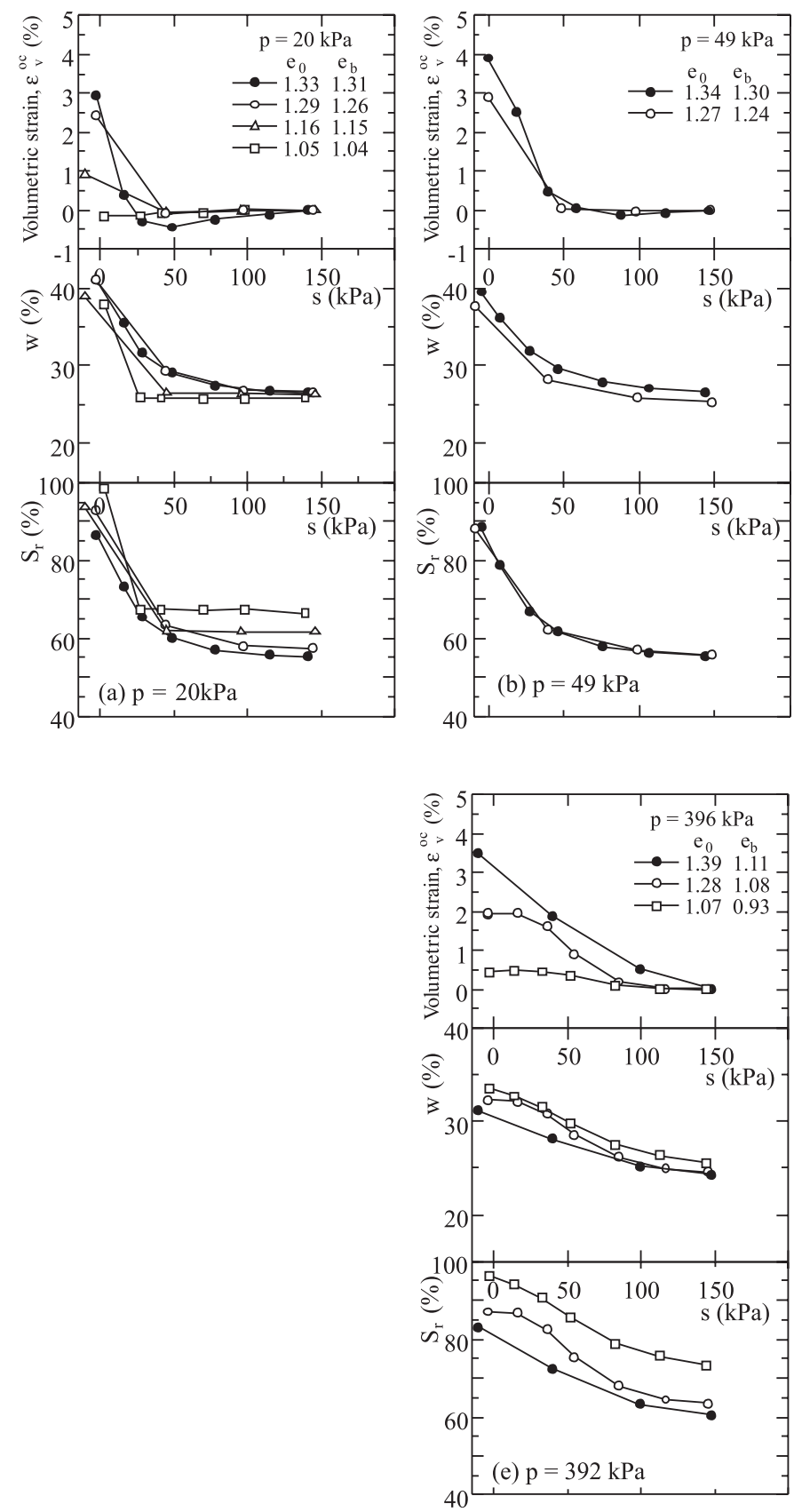

crease of the suction. Unlike the volumetric strain, the degree of saturation changes more gradually with decreasing suction, regardless of the values of the mean net stress and the initial density. However, when the degree of saturation becomes very high, for example about $85 \%$ or above, the increment in the volume contraction due to the suction reduction is very small. That is to say, when the degree of saturation achieves about $85 \%$ or above, the volume contraction no long occurs for further suction reduction. It can be seen from Fig. 13 that, even if the suction approaches zero, the degree of saturation is smaller than $100 \%$. This is particularly true for loosely compacted specimens (see Figs. $13 c-13 e$ ). Ng and Pang (2000) reported similar results from their oedometer tests. The reason for this differ-
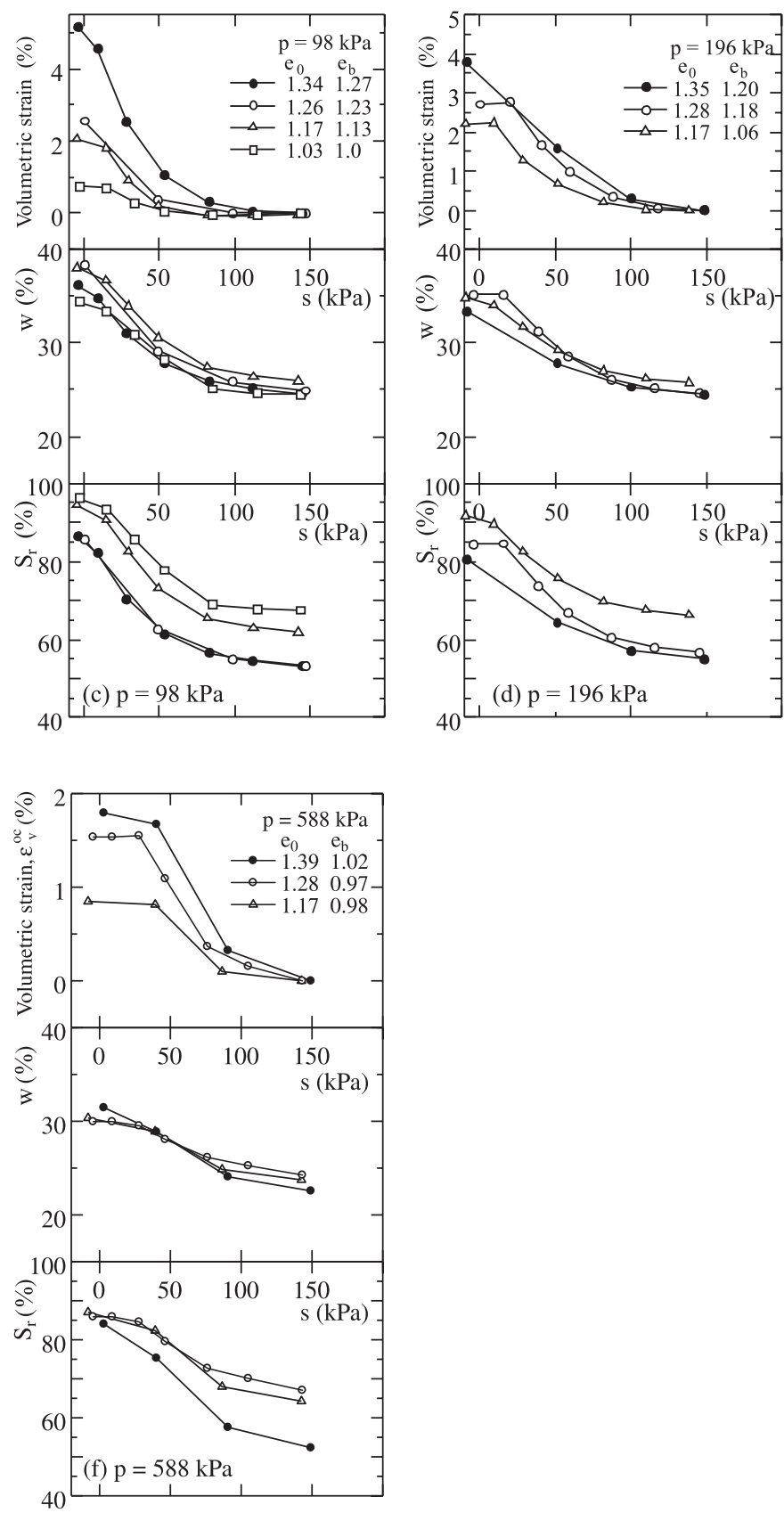

ence between loose and dense specimens is that it is more difficult for capillary forces to displace the air trapped in the large pores than in small pores, and that the ink-bottle effect due to geometric nonuniformity of individual pores is likely to be more pronounced in loose specimens than in dense ones.

From the relationship between the measured suction and the water content in Fig. 13, it can be seen that the water content is about $25 \%$ at the beginning of the wetting for all the tests, and the values at the ending of the wetting vary from $40 \%$ to $30 \%$, with a lower final water content corresponding to a higher isotropic stress at which the wetting was initiated. It is more difficult to identify the influence of the initial density on the soil-water characteristic curve ex- 
Fig. 14. Soil-water characteristic curves during the suction reduction at different stresses for the same initial density.

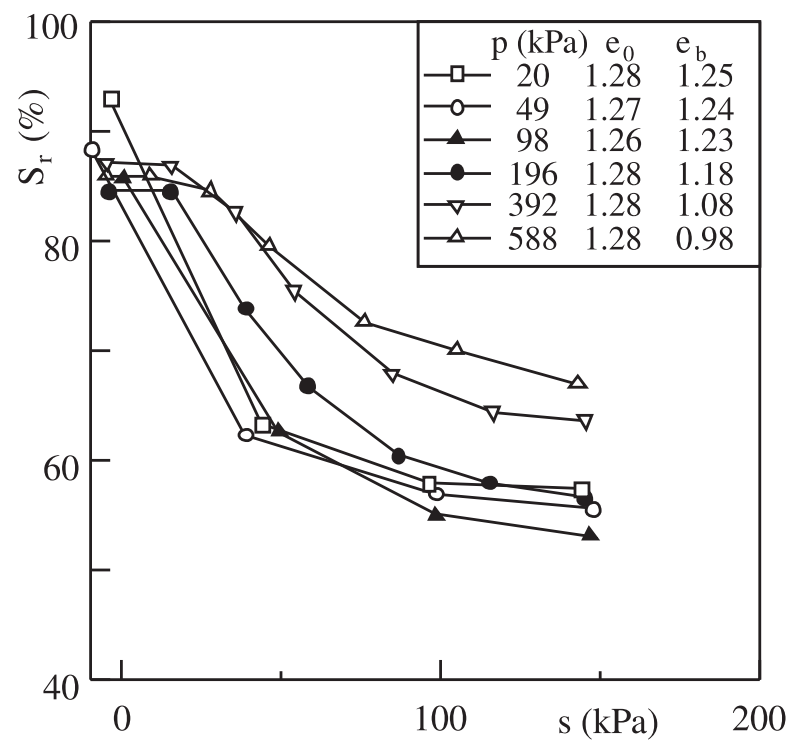

Fig. 15. Soil-water characteristic curves for the same void ratio at beginning of the collapse.

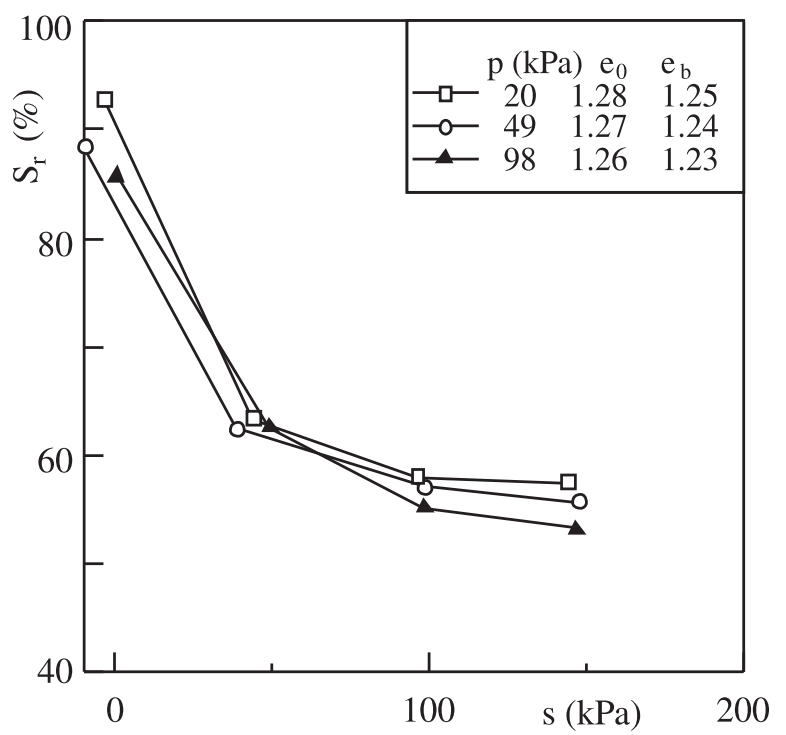

pressed in terms of water content. However, it is relatively easy to note the upward shift of the $S_{\mathrm{r}}-s$ curves with increasing initial density. A decrease in the void ratio implies a decrease in connecting passageways between voids, and hence an increase in the air-entry value ( $\mathrm{Ng}$ and Pang 2000). Vanapalli et al. (1999) reported similar results from drying testing of specimens compacted dry of the optimum water content.

Figure 14 shows the measured suction versus the degree of saturation during wetting of specimens compacted at the same initial density. The curve shifts up with increasing isotropic stress. However, if we extract the curves with approximately the same void ratio at the beginning of wetting, such as those shown in Fig. 15, it can be seen that, even if the
Fig. 16. Soil-water characteristic curves for different void ratios at beginning of the collapse.

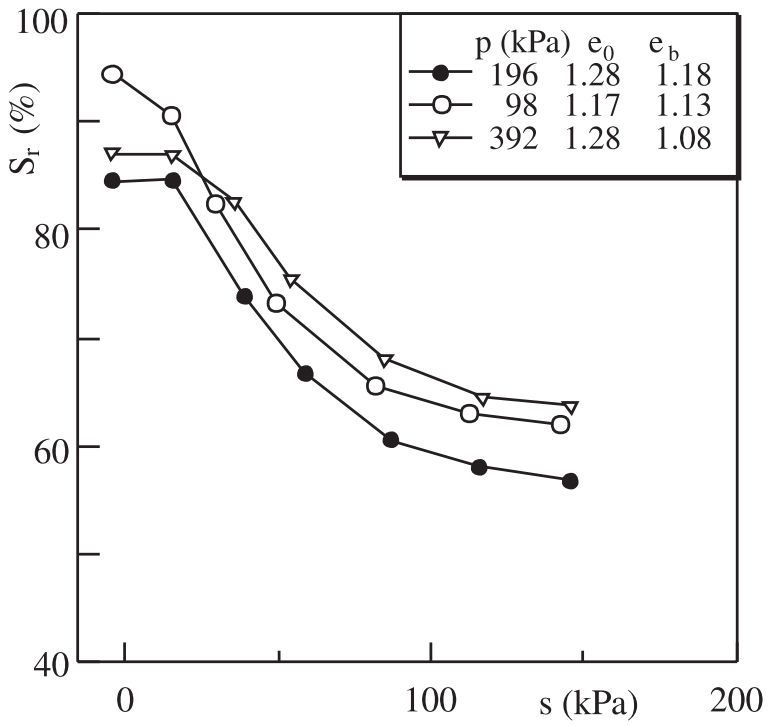

Fig. 17. Principal strains versus stress ratio and volumetric strain for triaxial compression tests including collapse test $(p=196 \mathrm{kPa})$.

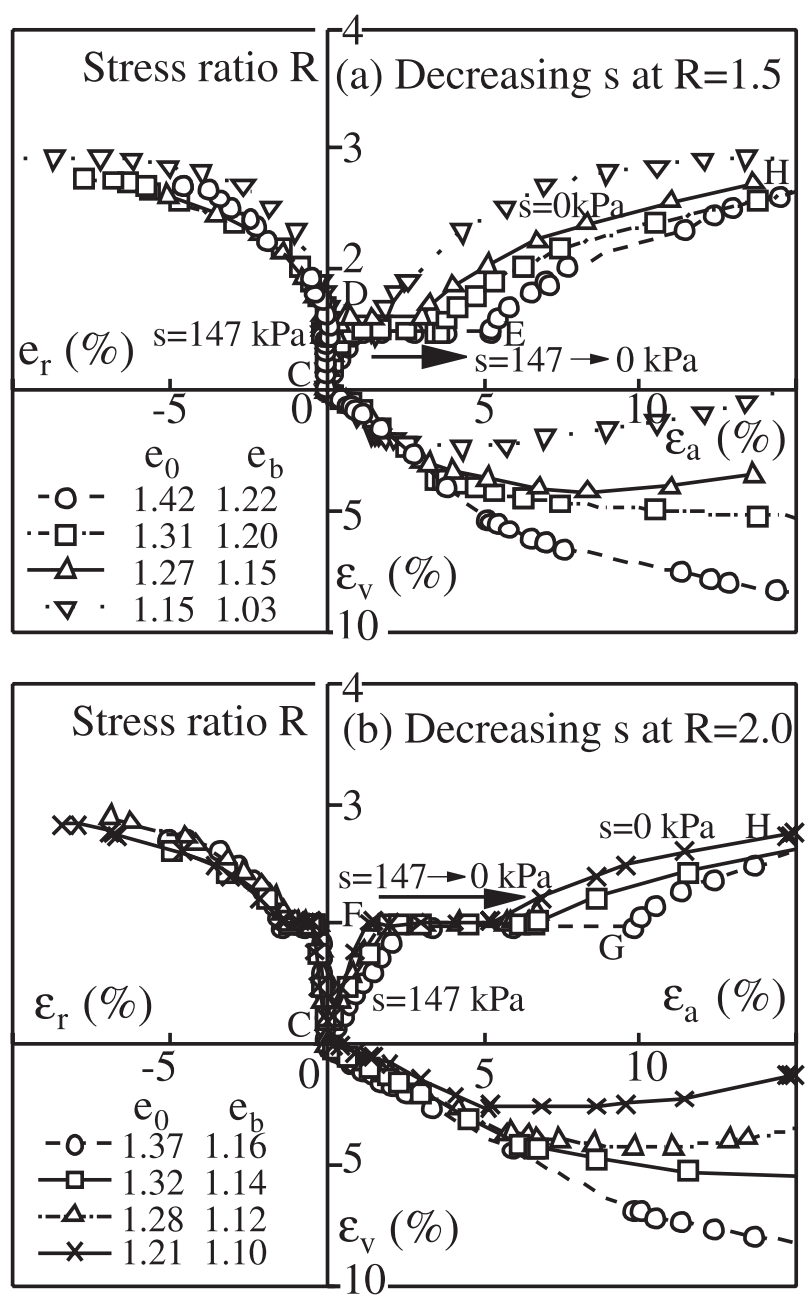


Fig. 18. Collapse behaviour during wetting under triaxial compression stress states.

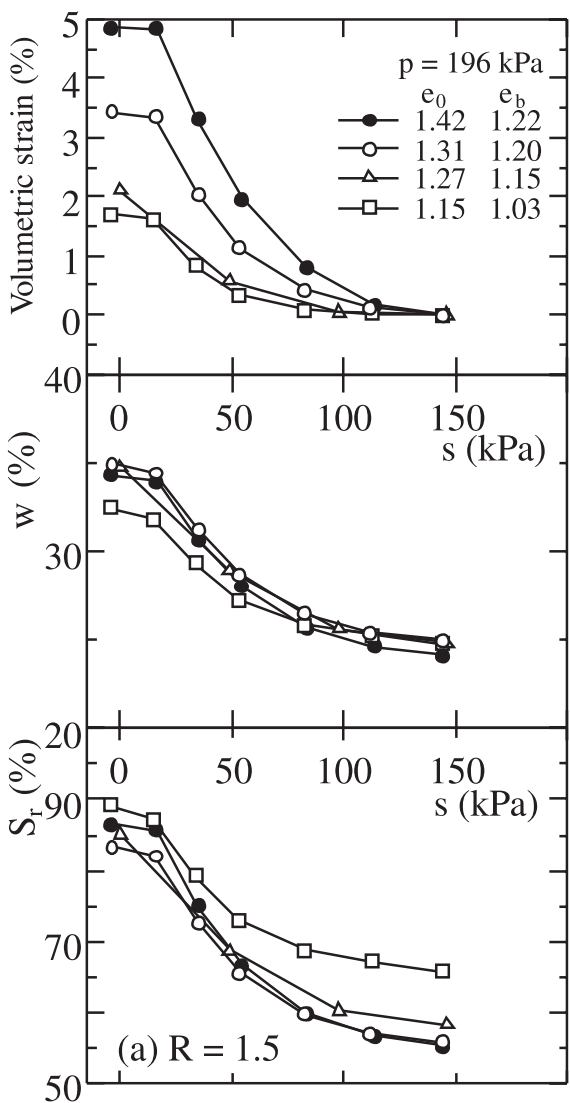

stress is different, the soil-water characteristic curve is almost the same. Figure 16 also confirms that the location of the soil-water characteristic curve on a plot of the degree of saturation versus suction is directly dependent upon the void ratio before wetting. That is to say, the curve for wetting at the isotropic stress of $98 \mathrm{kPa}$ is higher than that at the stress of $196 \mathrm{kPa}$ because the value of $e_{\mathrm{b}}$ under $p=98 \mathrm{kPa}$ is less than that under $p=196 \mathrm{kPa}$. Therefore, the soil-water characteristic curve is only indirectly related to stress levels, as an increase in the mean net stress results in a decrease in the void ratio.

\section{Collapse behaviour in anisotropic stress states}

To investigate collapse behaviour of the unsaturated compacted clay under anisotropic stress states, a series of triaxial compression tests and triaxial extension tests were conducted before the suction reduction. In triaxial compression tests the axial stress is greater than the radial stress, whereas the radial stress is greater than the axial stress in triaxial extension tests.

Figure 17 shows the relationships between the principal strains and the stress ratio and between the axial strain and the volumetric strain obtained from triaxial compression tests that follow the stress paths CDEH and CFGH in Fig. $7 b$, respectively. In Fig. 17 and subsequent figures, $\sigma_{\mathrm{a}}$ and $\sigma_{\mathrm{r}}$ are the axial and radial net stresses, respectively; $R=\sigma_{\mathrm{a}} / \sigma_{\mathrm{r}}$ is the principal stress ratio for triaxial compression; and $\varepsilon_{\mathrm{a}}, \varepsilon_{\mathrm{r}}$, and $\varepsilon_{\mathrm{v}}$ are the axial, radial, and volumetric strains, respectively. The first quadrant of the figure shows

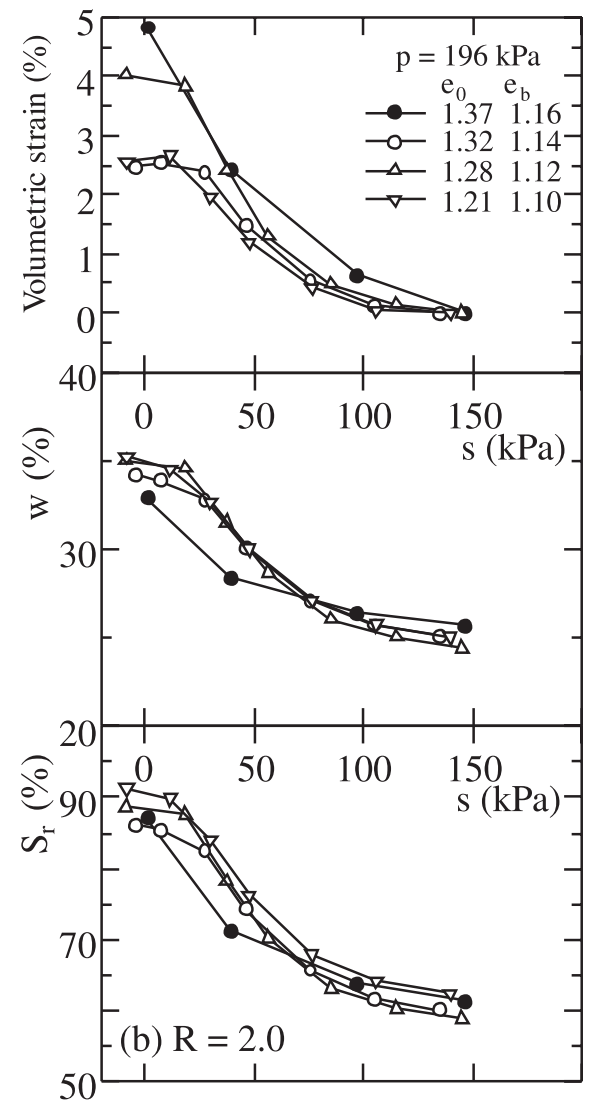

the relationship between the axial strain, $\varepsilon_{\mathrm{a}}$, and the principal stress ratio, $\sigma_{\mathrm{a}} / \sigma_{\mathrm{r}}$. The second quadrant shows the relationship between the radial strain, $\varepsilon_{\mathrm{r}}$, and the principal stress ratio, $\sigma_{\mathrm{a}} / \sigma_{\mathrm{r}}$; and the fourth quadrant shows the relationship between the axial strain, $\varepsilon_{\mathrm{a}}$, and the volumetric strain, $\varepsilon_{\mathrm{v}}$. The imposed stress paths and wetting paths for the test results in Fig. 17 are shown in Fig. $7 b$, where path $\mathrm{AB}$ is an equalization process to establish the suction to $147 \mathrm{kPa}$; path $\mathrm{BC}$ is an isotropic loading path to increase the mean net stress $p$ to $196 \mathrm{kPa}$; paths $\mathrm{CD}$ and CF represent the increases in the deviator stress to a stress ratio of 1.5 and 2.0, respectively, while the suction and the mean net stress are kept constant; paths DE and FG are wetting paths where the suction is reduced from $147 \mathrm{kPa}$ to $0 \mathrm{kPa}$ while the axial and radial net stresses are kept constant; and finally, paths $\mathrm{EH}$ and $\mathrm{GH}$ represent deviator stress increases until failure while the suction is kept at zero and the mean net stress is kept at $196 \mathrm{kPa}$. Figures $17 a-17 b$ show only the test results along the stress paths $\mathrm{CDEH}$ and $\mathrm{CFGH}$, respectively.

It can be seen from Fig. 17 that the suction reduction at a stress ratio of 1.5 causes a small positive (contraction) radial strain, but at a stress ratio of 2.0 a negative (swelling) radial strain, irrespective of the initial density. It can be inferred that if the collapse takes place under $K_{0}$ condition (i.e., no radial strain occurs), the stress ratio should be between 1.5 and 2.0, independent of the initial void ratio. The suction reduction causes a larger volumetric strain and a larger shear strain for a looser specimen. The shear strain caused by the suction reduction is larger at a higher stress ratio, while it is difficult to note the relation between the stress ratio and the 
Fig. 19. Collapse strain versus initial void ratio at different stress ratios under triaxial compression $(p=196 \mathrm{kPa})$.
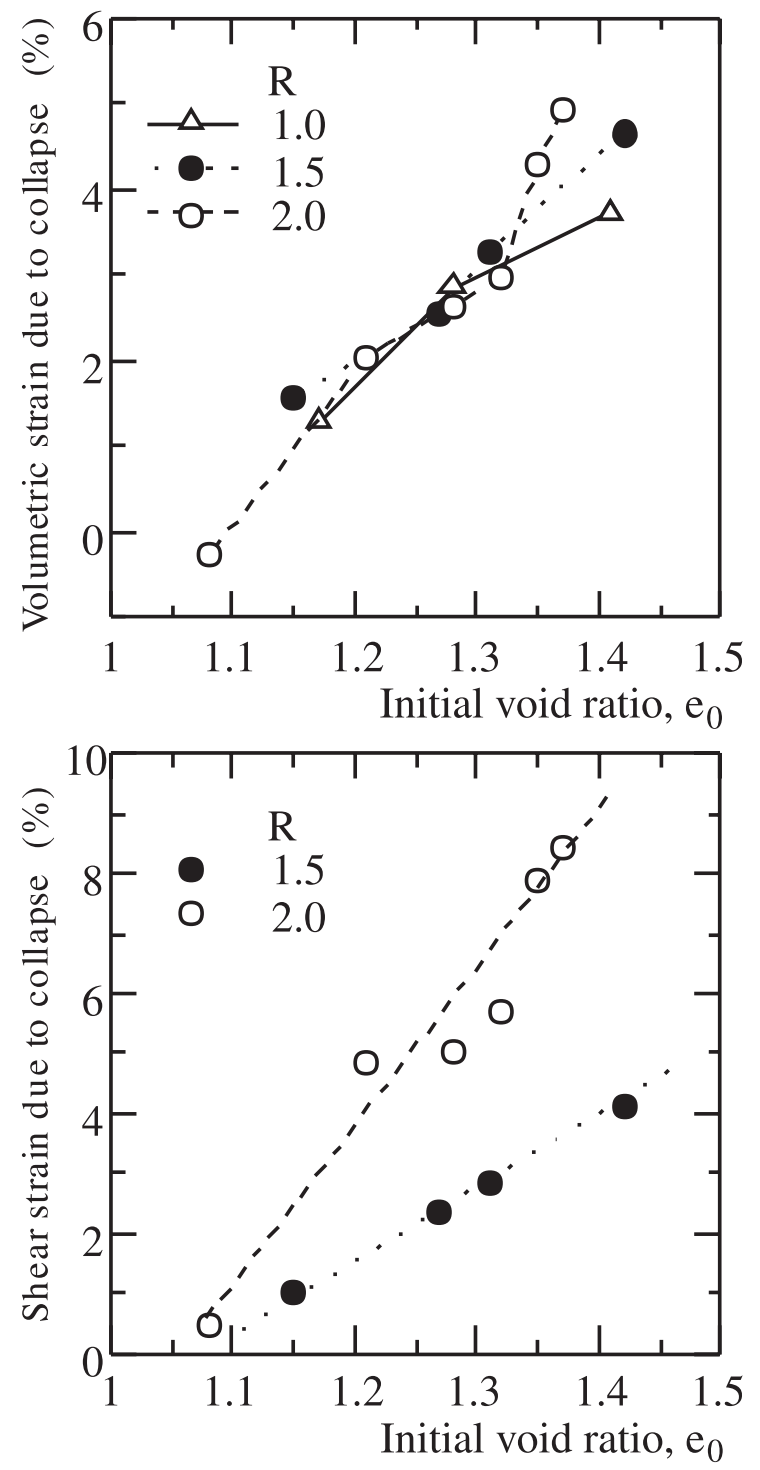

volumetric strain caused by the suction reduction. The points $(\nabla)$ shown in Fig. $17 a$ show the test results for an initial void ratio of 1.15 . The specimen volume initially contracts and subsequently dilates, rather than consistently contracting as in a triaxial shearing process, which means that the compacted clay specimens with different initial densities may have different dilatancy behaviour, even under the same mean net stress and the same suction.

The results for the wetting (suction reduction) process are redrawn in Fig. 18. The collapse volumetric strain, the water content, and the degree of saturation are replotted against the suction. The collapse behaviour under triaxial compression stresses is not much different from that under isotropic stresses as shown in Fig. 13. In general, a looser specimen corresponds to a larger collapse volumetric strain and a lower curve of suction versus the degree of saturation. In addition, the wetting-caused volume collapse under triaxial compression stresses is small both at relatively high suction levels and at suctions around zero and is largest at interme-
Fig. 20. Principal strains versus stress ratio and volumetric strain for triaxial extension tests including collapse test ( $p=196 \mathrm{kPa})$.
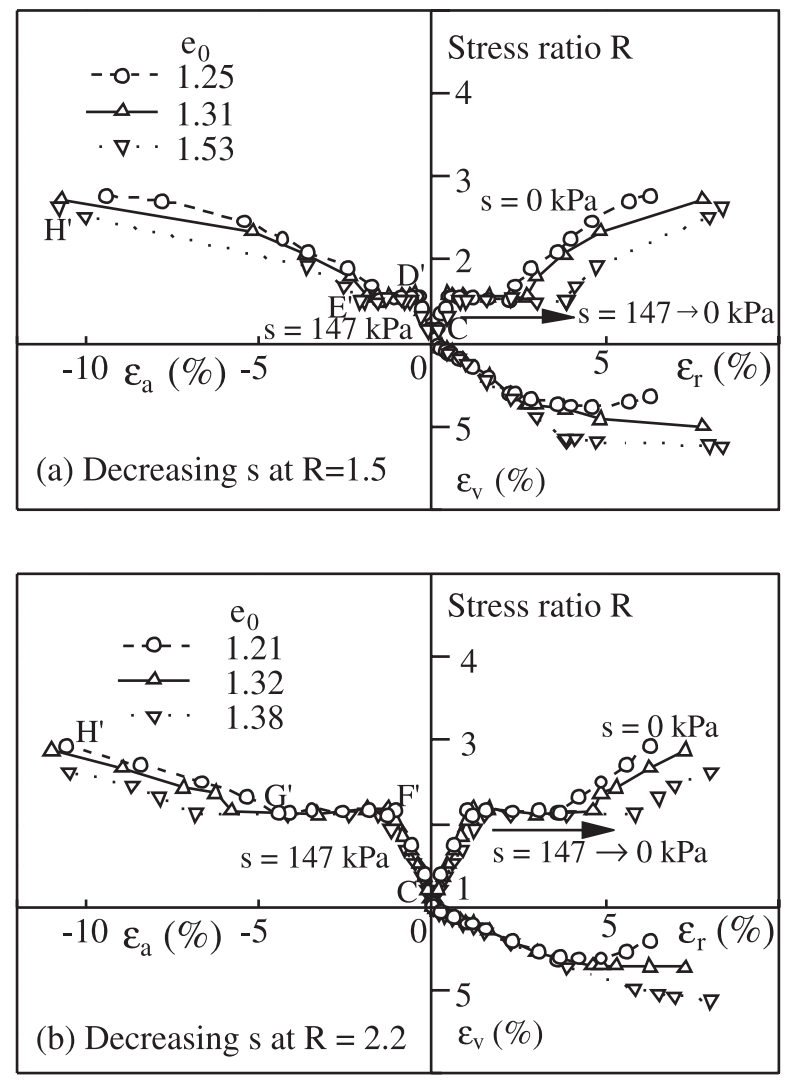

diately low suction levels. Again, it is difficult to identify the influence of the density on the soil-water characteristic curve expressed in terms of water content.

Figure 19 shows the collapse strain as a function of the initial void ratio, with data rearranged from Figs. 11 and 17. It can be seen that, under the same mean net stress, a smaller initial void ratio leads to a smaller collapse volumetric strain. This relationship is true irrespective of the stress ratio at which the suction reduction is applied. This behaviour is similar to the results reported by Lawton et al. (1991) who conducted triaxial tests on an unsaturated clayey sand by controlling the initial saturation degree. However, the shear strain caused by wetting seems to depend both on the initial void ratio and on the stress ratio. For specimens compacted to the same initial void ratio, a larger stress ratio at which the suction is reduced leads to a larger collapse shear strain. These results can be used to evaluate the amount of collapse strains in practical engineering when the initial density of compacted soils and the stress state are known. That is, if the initial density and the stress state under which the wetting occurs are known, the final collapse strains can be evaluated from Fig. 19.

In Fig. 20, the principal strains are plotted against the stress ratio and the volumetric strain obtained from triaxial extension tests. The imposed stress paths are the path (a) $\mathrm{CD}^{\prime} \mathrm{E}^{\prime} \mathrm{H}^{\prime}$ and $(b) \mathrm{CF}^{\prime} \mathrm{G}^{\prime} \mathrm{H}^{\prime}$, respectively, in Fig. $7 b$. Here the stress ratio is defined as $R=\sigma_{\mathrm{r}} / \sigma_{\mathrm{a}}$ for triaxial extension tests. In contrast to the results of triaxial compression tests in Fig. 17a, the suction reduction at the stress ratio 
Fig. 21. Collapse behaviour during wetting under triaxial extension stress states.

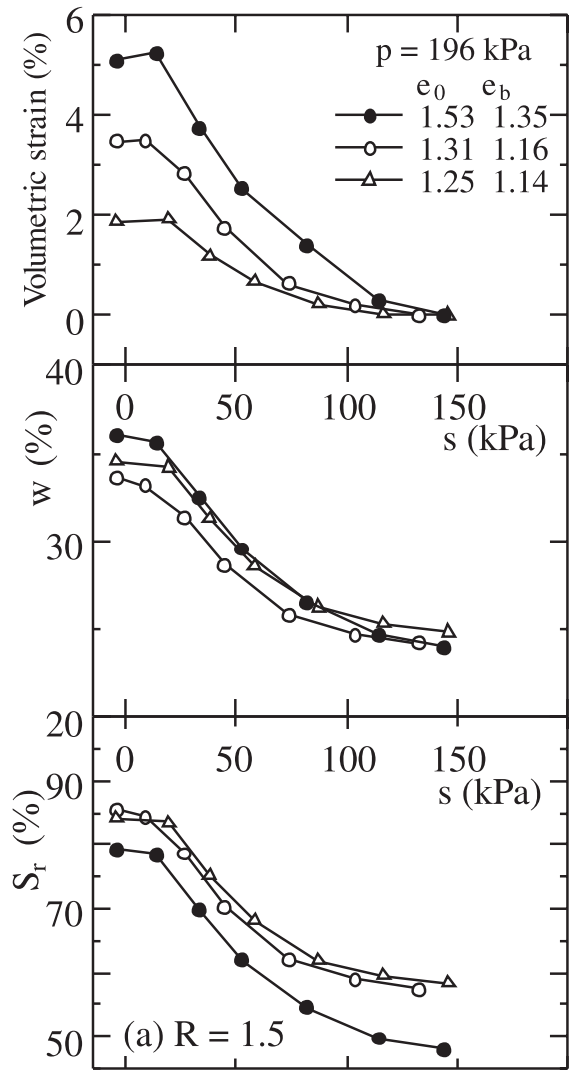

of 1.5 caused an axial swelling in the triaxial extension tests. The results for the wetting path only are redrawn in Fig. 21, where the collapse volumetric strain, the water content, and the degree of saturation are plotted against the suction. The collapse behaviour under triaxial extension stress states (Fig. 21) is similar to those under isotropic (Fig. 13) and triaxial compression (Fig. 18) stress states. That is, a looser specimen results in a larger collapse volumetric strain and a lower soil-water characteristic curve (in terms of the degree of saturation). The volumetric collapse strain is small both at relatively high suction levels and at suctions near zero, but is largest at intermediately low suction levels.

According to the test results it can be seen that the relation between the suction and the degree of saturation during wetting is mainly dependent upon the density. Figure 22 shows the measured suction plotted against the degree of saturation during wetting, with data from Figs. 13, 18, and 21 . In the figure, $e_{\mathrm{ba}}$ is the average void ratio at the beginning of the suction reduction in each figure; Comp and Ext denote the results from triaxial compression tests and triaxial extension tests, respectively. It can be seen that the soilwater characteristic curves during wetting are almost the same for soil specimens with a similar density and are not directly dependent upon the stress state under which the suction change takes place.

Figure 23 shows the collapse strains plotted as a function of the initial void ratio for different stress ratios, extracted from Figs. 11 and 20. The results shown in Fig. 23 for triaxial extension tests are similar to those in Fig. 19 for triaxial compression tests.

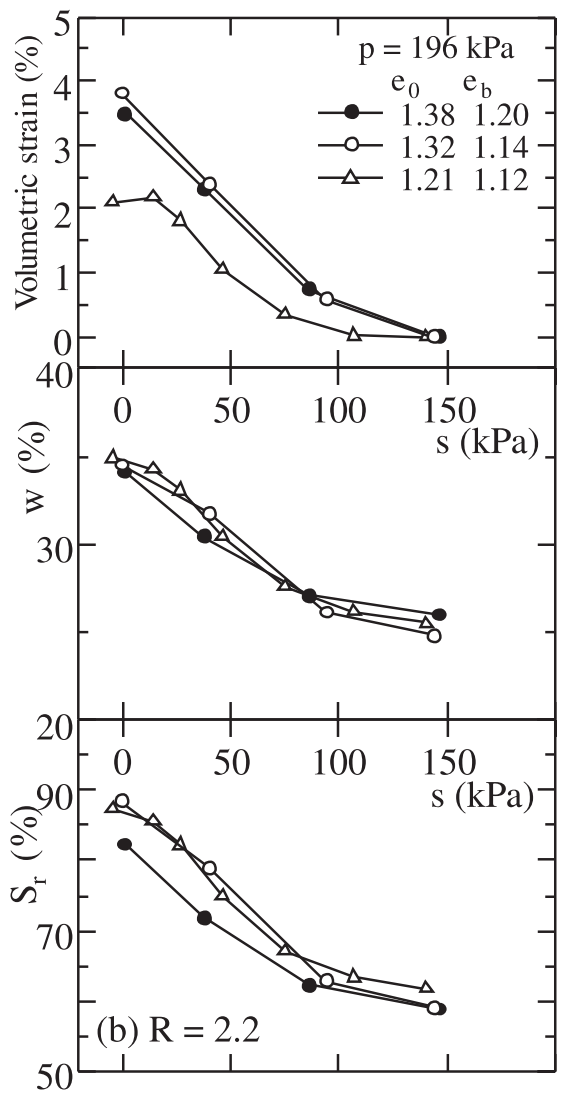

\section{Conclusions}

An experimental program has been carried out to investigate the effects of density and stress condition on the hydraulic and mechanical behaviour during the collapse of a compacted clay. The following conclusions concerning the collapse behaviour can be drawn from this study.

(1) The collapse deformation due to a suction reduction depends mainly upon the density and stress state under which the collapse occurs, while the soil-water characteristic curve expressed by the relation between the suction and the degree of saturation depends mainly upon the current density and not directly upon the stress state.

(2) During the wetting process, the soil-water characteristic curves plotted in the plane of suction versus degree of saturation are shifted upward with increasing density of the compacted soil. The occurrence of the volume contraction due to a suction reduction is more simultaneous with changes in the degree of saturation than the changes in the suction.

(3) The volume change due to a suction decrease mainly depends on the mean net stress and the initial void ratio, and a maximum collapse occurs when the mean net stress equals the initial yielding net stress of the unsaturated soil.

(4) For unsaturated specimens compacted at the same initial density, the compression curves obtained for specimens saturated at different mean net stresses are more or less the same. The compression curve for initially unsaturated specimens wetted to zero suction is shifted down somewhat with increasing initial density. 
Fig. 22. Soil-water characteristic curves on wetting at different stress ratios $R$ under $p=196 \mathrm{kPa}$.
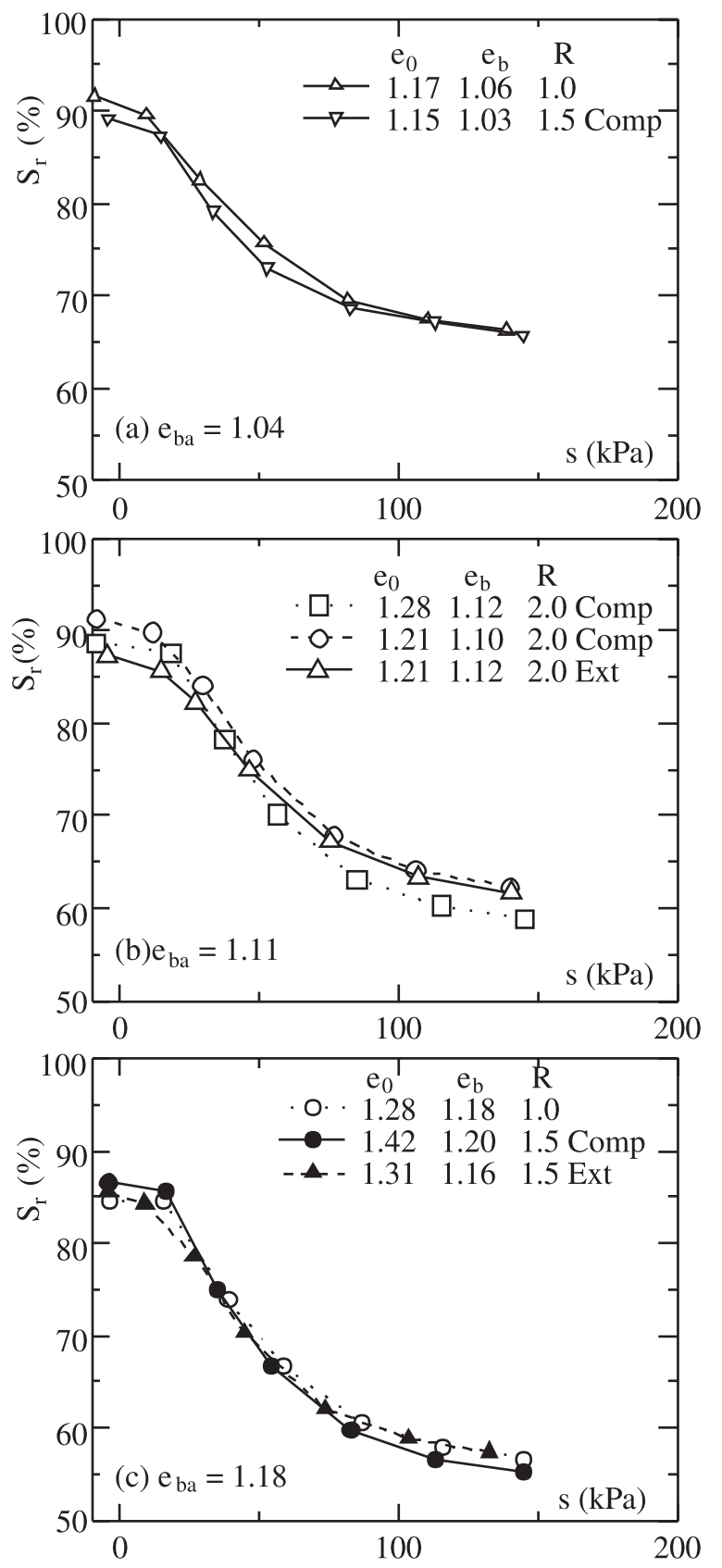

(5) Under the same initial suction and mean net stress, a looser specimen results in a larger volume collapse, irrespective of the stress ratio at which the suction is reduced, while the shear collapse deformation caused by a suction reduction depends upon both the stress ratio and the density.

\section{Acknowledgments}

Some of the experimental work described in this paper was conducted at the Nagoya Institute of Technology, Japan over the past 7 years. The first author wishes to thank Professor Hajime Matsuoka at the Nagoya Institute of Technology for his encouragement and support of this work. The
Fig. 23. Collapse strain versus initial void ratio at different stress ratios under triaxial extension $(p=196 \mathrm{kPa})$.
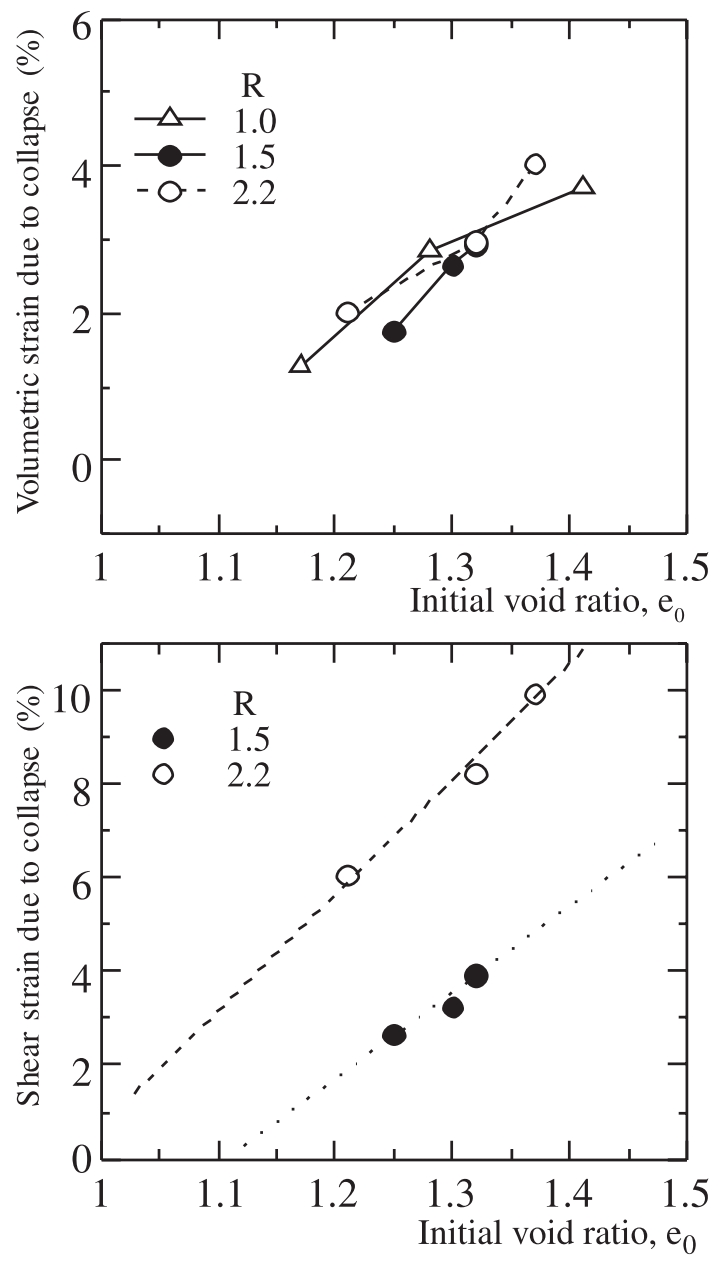

authors also wish to thank Dr. Hongbin Cui, a former postgraduate student at the Nagoya Institute of Technology, for his help with a part of the experimental work. The research described in this paper was partially supported by the $\mathrm{Na}-$ tional Natural Science Foundation of China (No. 10572081) and by the Australian Research Council (DP0344417). The authors also wish to thank the anonymous reviewers for their constructive and helpful comments.

\section{References}

Alonso, F.E., Gens, A., and Josa, A. 1990. A constitutive model for partially saturated soils. Géotechnique, 40(3): 405-430.

Cui, Y.J., and Delage, P. 1996. Yielding and plastic behaviour of an unsaturated compacted silt. Géotechnique, 46(2): 291-311.

Hilf, J.W. 1956. An investigation of pore water pressure in compacted cohesive soils. US Department of Interior, Bureau of Reclamation, Technical Memorandum, No. 654.

Kato, S., and Kawai, K. 2000. Deformation characteristics of a compacted clay in collapse under isotropic and triaxial stress state. Soils and Foundations, 40(5): 75-90.

Lawton, E.C., Fragaszy, R.J., and Hardcastle, J.H. 1991. Stress ratio effects on collapse of compacted clayey sand, Journal of Geotechnical Engineering, ASCE, 117(5): 714-730. 
Maatouk, A., Leroueil, S., and La Rochelle, P. 1995. Yielding and critical state of a collapsible unsaturated silty soil. Géotechnique, 45(3): 465-477.

Ng, C.W.W., and Pang, Y.W. 2000. Experimental investigations of the soil-water characteristics of a volcanic soil. Canadian Geotechnical Journal, 37: 1252-1264.

Padilla, J.M., Perera, Y.Y., Houston, W.N., Perez, N., and Fredlund, D.G. 2006. Quantification of air diffusion through high air-entry ceramic disks. In Proceedings of the 4th International Conference on Unsaturated Soils, Arizona. Edited by G. Miller, C.E. Zapata, S.L. Houston, and D.G. Fredlund. Geotechnical Special Publication No. 147, Vol. 2, pp. 18521863.

Pereira, J.H.F., and Fredlund, D.G. 2000. Volume change behavior of collapsible compacted gneiss soil. Journal of Geotechnical and Geoenviromental Engineering, ASCE, 126(10): 907-916.

Rampino, C., Mancuso, F., and Vinale, F. 1998. Behaviour of a compacted silty sand during suction controlled tests. In Proceedings of the 2nd International Conference on Unsaturated Soils, Beijing, China. International Academic Publishers, Vol. 1, pp. 108-113.

Sheng, D.C., Sloan, S.W., and Gens, A. 2004. A constitutive model for unsaturated soils: thermomechanical and algorithmic aspects. Computational Mechanics, 33: 453-465.

Sivakumar, V., and Wheeler, S.J. 2000. Influence of compaction procedure on the mechanical behaviour of an unsaturated compacted clay, Part 1: Wetting and isotropic compression. Géotechnique, 50(4): 359-368.

Sun, D.A., and Sheng, D.C. 2005. An elastoplastic hydromechanical model for unsaturated compacted soils. In Proceed- ings of the International Symposium on Advanced Experimental Unsaturated Soil Mechanics, Trento, Italy. Edited by A. Tarantino, E. Romero, and Y.J. Cui. A.A. Balkema, Rotterdam, the Netherlands. pp. 249-255.

Sun, D.A., Matsuoka, H., Yao, Y.P., and Ichihara, W. 2000. An elastoplastic model for unsaturated soil in three-dimensional stresses. Soils and Foundations, 40(3): 17-28.

Sun, D.A., Matsuoka, H., and Xu, Y.F. 2004. Collapse of compacted clay in suction-controlled triaxial tests. Geotechnical Testing Journal, ASTM, 27(4): 362-370.

Vanapalli, S.K., Fredlund, D.G., and Pufahl, D.E. 1999. The influence of soil structure and stress history on the soil-water characteristics of a compacted till. Géotechnique, 49(2): 143-159.

Vaunat, J., Romero, E., and Jommi, C. 2000. An elastoplastic hydro-mechanical model for unsaturated soils. In Proceedings of an International Workshop on Unsaturated Soils: Experimental Evidence and Theoretical Approaches in Unsaturated Soils, Trento, Italy. Edited by A. Tarantino and C. Mancuso. A.A. Balkema, Rotterdam, the Netherlands. pp. 121-138.

Wang, Q., Pufahl, D.E., and Fredlund, D.G. 2002. A study of critical state on an unsaturated silty soil. Canadian Geotechnical Journal, 39: 213-218.

Wheeler, S.J., and Sivakumar, V. 1995. An elasto-plastic critical state framework for unsaturated soil. Géotechnique, 45(1): 35-53.

Wheeler, S.J., and Sivakumar, V. 2000. Influence of compaction procedure on the mechanical behaviour of an unsaturated compacted clay, Part 2: Shearing and constitutive modeling. Géotechnique, 50(4): 369-376. 